\title{
CRISE CONSTITUINTE: AS REFORMAS ADMINISTRATIVAS E OS AJUSTES FISCAIS NO CONTEXTO DO ESTADO DE EXCEÇÃO ECONÔMICO
}

\section{CONSTITUENT CRISIS: THE ADMINISTRATIVE REFORMS AND THE FISCAL ADJUSTMENTS IN A STATE OF ECONOMIC EXCEPTION}

\section{Daniel Allan Miranda Borba ${ }^{1}$}

Data de Recebimento: 30/04/2018

Data de Aprovação: 07/09/2018

\section{RESUMO}

Com o aprofundamento da crise fiscal e da própria crise do Estado na década de 1990, além da ineficiência do serviço público, as "transformações" trazidas pela Constituição Federal de 1988 não foram acompanhadas das necessárias mudanças normativas, institucionais e culturais, de forma que não logrou romper com a pecha da corrupção e ausência que caracteriza o Estado brasileiro. Os governos pós-Constituição de 1988 imprimiram as marcas do

\footnotetext{
${ }^{1}$ Mestre em Direito pela Universidade Federal de Alagoas - UFAL. Procurador do Município de Maceió Professor do Centro Universitário CESMAC. Av. Comendador Gustavo Paiva, n 3741, Mangabeiras, CEP: 57037-285, Maceió/AL. +5582993218160. 
neoliberalismo através de profundas mudanças constitucionais que, atualmente, inviabilizam as promessas constitucionais, através da implementação de um Estado mínimo, desengajando-se do Estado de Bem-Estar social a partir do foco no ajuste fiscal. Este artigo se propõe a demonstrar que as reformas constitucionais que têm como base o ajuste fiscal, sobretudo a Emenda Constitucional n ${ }^{\circ}$ 95/2016, são promovidas em virtude do permanente estado de exceção econômico vivenciado especialmente pelos países da América Latina, o que acaba por desfazer os projetos originários previstos pelo poder constituinte, configurando-se na crise constituinte, porquanto as decisões são tomadas de acordo com a conveniência dos interesses econômicos e não de acordo com a vontade do povo. Para alcançar os objetivos aqui propostos, adotou-se a metodologia jurídica, o método descritivo, a pesquisa documental, a técnica da documentação indireta e a pesquisa bibliográfica.

\section{PALAVRAS-CHAVE}

Neoliberalismo. Gerencialismo. Poder constituinte. Emenda Constitucional no 95/2016.

\section{ABSTRACT}

With the deepening of the fiscal crisis and the state crisis itself in the 1990s, beyond the inefficiency of the public service, the "transformations" brought by the Federal Constitution of 1988 weren't accompanied by the necessary normative, institutional and cultural changes, in a way that did not manage to break with the corruption and absence that characterize the Brazilian State. The post-Constitution governments of 1988 have imprinted the hallmarks of neoliberalism through profound constitutional changes that currently make the constitutional promises unfeasible through the implementation of a minimal state, disengaging from the welfare state as from the focus on fiscal adjustment. This article proposes to demonstrate that the constitutional reforms based on fiscal adjustment, mainly the Constitutional Amendment $n^{\circ}$ 95/2016, are taken by virtue of the permanent state of economic exception experienced especially by the countries of Latin America, which undo the original projects foreseen by the constituent power, forming itself in the constituent crisis as 
long as the decisions are made according to the convenience of the economic interests and not according to the will of the people. In order to achieve the objectives proposed here, we adopted the legal methodology, the descriptive method, the documentary research, the indirect documentation technique and the bibliographic research.

\section{KEYWORDS}

Neoliberalism. Managerialism. Constituent power. Constitutional Amendment $n^{\circ}$ 95/2016. 


\section{INTRODUÇÃO}

Nas últimas décadas, a globalização, o neoliberalismo e o neocolonialismo vêm transformando o papel do Estado, em especial nos países periféricos. Nestes, de um Estado agigantado, interventor e provedor, abre espaço para um Estado regulador, influenciado pelas forças de mercado.

Tais mudanças são observadas através das diversas reformas administrativas que foram implementadas ao longo de menos de um século da história do Brasil, sobremodo as posteriores à Constituição de 1988, que se utilizaram de discursos voltados a uma mudança institucional visando à melhoria dos serviços públicos, mas, no entanto, tinham como principal objetivo o simples ajuste fiscal a partir de um maior controle e da redução dos gastos públicos, bem como a diminuição do tamanho do Estado.

A importância que deve ser dada às reformas administrativas gira em torno da realização ou não dos valores e garantias previstos na Constituição, uma vez que é através da Administração Pública que se garante a efetivação dos direitos fundamentais nela previstos.

Estas reformas são elaboradas, geralmente, mediante mudanças na Constituição, num contexto de crise constituinte no qual o titular do poder já não é mais o povo, mas sim os poderes políticos e econômicos hegemônicos, em virtude do estado de exceção econômico permanente em que os vivem países latino-americanos.

Cumpre verificar se as reformas constitucionais têm o poder de desfazimento dos principais objetivos previstos pelo poder constituinte originário, em especial, se as reformas administrativas podem violar o direito fundamental ao desenvolvimento, e, em última análise, a própria dignidade da pessoa humana, ao dificultarem ou mesmo inviabilizarem a prestação dos serviços públicos com qualidade.

Nesses termos, o presente trabalho tem como principal objetivo analisar a crise constituinte no contexto das reformas administrativas, mais especificamente, da última reforma, que visou tão somente ao ajuste fiscal a partir da implementação de um rigoroso regime fiscal, por meio da Emenda Constitucional no 95/2016. 
Ainda que não se possa considerar o mero ajuste fiscal como uma reforma administrativa, justifica-se serem tratados em conjunto, uma vez que um repercute no outro, já que a redução de despesas implica, necessariamente, um remodelamento da Administração. Ademais, o equilíbrio fiscal é um dos grandes objetivos da reforma gerencial.

Inicialmente, serão apresentados os paradigmas utilizados para a Administração Pública na Constituição de 1988, para, em seguida, tecer-se uma breve análise das principais reformas administrativas constitucionais que resultaram em ajustes fiscais. Também será analisado o fenômeno da crise constituinte em razão do estado de exceção econômico permanente. Por fim, serão apresentadas algumas possíveis soluções para o problema da crise fiscal e da crise constituinte, tendo por base noções da democracia participativa como forma de controle das reformas administrativas.

Para alcançar os objetivos aqui propostos, adotou-se a metodologia jurídica, com base na abordagem observacional; além do método descritivo, que apenas registra e descreve os fatos observados no caso concreto. Também será realizada a pesquisa documental das normas e decisões inerentes à matéria. Será utilizada a técnica da documentação indireta, uma vez que a coleta de dados ficará restrita aos documentos escritos. A pesquisa bibliográfica será realizada em livros, artigos científicos, jornais e revistas já publicados.

\section{PARADIGMAS DA CONSTITUIÇÃO DEMOCRÁTICA DE 1988: ADMINISTRAÇÃO PÚBLICA E DESENVOLVIMENTO}

Em menos de um século, a Administração Pública brasileira passou por diversas transformações de cunho normativo e institucional, todas com profundas repercussões nas suas constituições; entretanto, suas implementações não lograram o êxito esperado, tanto que novas reformas são tentadas a todo instante.

Tais mudanças são necessárias, pois, apesar do desencantamento do Estado, ele ainda é bem sólido e volta à cena mesmo após seu declínio. Além disso, a prática contemporânea mostra que os Estados são primordiais e os melhores agentes para a tomada de decisões, ainda que esta visão de Estado 
fortalecido seja considerada um obstáculo para os futuristas da gestão mundial (ARNOUD, 1999, p. 174-176).

Foi no governo Vargas, em 1933, que se iniciaram os estudos de reforma da Administração Pública, com vistas a implantar uma burocracia weberiana no Brasil do tipo racional e moderna, tendo a industrialização como meio de desenvolvimento, com papéis na regulamentação econômica e no tocante às novas atribuições impostas pelo sistema produtivo nacional e ao atendimento das demandas sociais exigidas pelo Estado de Bem-Estar ${ }^{2}$ (Welfare State) que se estava a implantar, "estabelecendo um 'padrão duplo', onde os altos escalões da burocracia seguiram esse padrão moderno enquanto os escalões inferiores ficam sujeitos às manipulações populistas e clientelistas" (PINHO, 1998, p. 60).

De acordo com Bresser-Pereira (2002, p. 81), essa forma de gerir a coisa pública é tida como não democrática, pois, apesar de ter como objetivo fundamental a proteção do Estado em face da corrupção e do nepotismo, a sua concepção, ao menos no Brasil de regime ditatorial, trouxe valores autoritários e acabou por não obter resultados satisfatórios.

A reforma do aparelho do Estado só acontece de verdade com o Decreto $n^{\circ}$ 200/1976, no período do Estado Burocrático-Autoritário, pois “contorna a rigidez das estruturas da administração direta" e introduz "o espírito gerencial privado na administração do setor paraestatal". Foi um período de maior intervenção do Estado na economia, criando um número de empresas estatais sem precedentes em todos os setores, seja no produtivo, seja na prestação de serviços públicos (PINHO, 1998, p. 64/65).

O declínio desse modelo Estado foi marcado pelo processo de "financeirização", que ganha força nos países desenvolvidos na década de setenta. Em especial após os choques do petróleo, quando se passa a sustentar que os problemas do Estado decorrem de seu intervencionismo, e, por tal razão, seria

\footnotetext{
${ }^{2}$ Sintetizando o seu papel, Bonavides (2014, p. 184-186) dispõe o seguinte: "coagido pela pressão das massas, pelas reivindicações que a impaciência do quarto estado faz ao poder político, confere, no Estado constitucional ou fora deste, os direitos do trabalho, da previdência, da educação, intervém na economia como distribuidor, dita o salário, manipula a moeda, regula os preços, combate o desemprego, protege os enfermos, dá ao trabalhador e ao burocrata a casa própria, controla as profissões, compra a produção, financia as exportações, concede crédito, institui comissões de abastecimento, provê necessidades individuais, enfrenta crises econômicas, coloca na sociedade todas as classes na mais estreita dependência de seu poderio econômico, político e social".
} 
necessária a implementação de políticas econômicas de liberalização da economia e a redução do tamanho do Estado (CANO, 2000, p. 25).

Tais medidas ganharam força com o resgate das teorias liberais de Adam Smith, que passaram a sustentar que "a mão invisível do mercado constituía o melhor recurso", visando ao benefício de todos. Tratava-se de uma "ideologia pró-mercado", pois o Estado seria falho ao se sujeitar às tendências de grupos de interesses, bem como por errar em suas decisões com relação aos investimentos e à acumulação do capital (HARVEY, 2008, p. 30).

Com isso, o "neoliberalismo" começa a ser implementado pouco a pouco nos mais diversos países, sob o argumento de que o desemprego era consequência do alto custo das proteções ao trabalho garantidas pelo Estado. Assim é que, em meados dos anos oitenta, Margaret Thatcher, na Grã-Bretanha, e Ronald Reagan, nos Estados Unidos, assumem a missão de restaurar a economia e iniciam um processo de desconstrução do Estado de Bem-Estar Social nos países desenvolvidos (HARVEY, 2008, p. 32).

Nesse período, muitos países em desenvolvimento também realizaram reformas administrativas em razão do declínio generalizado do desempenho, impulsionados pela insatisfação com os resultados do modelo keynesiano de desenvolvimento, pela crise do padrão do Welfare State e pelo modelo burocrático da gestão administrativa e da crise fiscal do Estado (REZENDE, 2004, p. 21-22).

Houve uma expansão sem precedentes do capitalismo como princípio organizativo das sociedades e da economia de quase todo o planeta, observando-se uma "mercantilização" das mais diversas áreas da vida social, na medida em que a sua força permitiu construir uma sociedade à sua imagem e semelhança, com impactos no campo popular e dos direitos civis nos países periféricos e o enfraquecimento do impulso democrático e redistribuicionista que caracterizou o capitalismo keynesiano, permitindo-se a transição para uma economia de mercado pós-capitalista (BORON, 2001, p. 1-2).

Neste contexto de expansão do capitalismo, os anos oitenta foram decisivos para a Administração Pública, pois em decorrência da crise econômica, havia a necessidade de uma nova configuração do Estado, tanto nos países desenvolvidos, em que o Estado restou agigantado pelas demandas sociais do 
Estado de Bem-Estar Social, como nos países periféricos, em que o Estado se ampliou para alavancar o crescimento econômico, devido à incapacidade operacional da burguesia. A fórmula neoliberal era a mesma: redução da função e papel do Estado, tendo em vista que para se enfrentar a crise econômica era necessário enfrentar a crise do Estado (PINHO, 1998, p. 68).

Apesar destes movimentos, em 1988, a Constituição brasileira, que pretendia ser dirigente, social e cidadã, consagrou o Estado Democrático de Direito, que trouxe como fundamentos a soberania, a cidadania, a dignidade da pessoa humana, os valores sociais do trabalho e da livre-iniciativa e o pluralismo político (BRASIL, 1988), garantindo diversos direitos sociais que dependiam de uma atuação forte e eficiente do Estado.

É importante ressaltar o seu espírito desenvolvimentista ao prever, já em seu preâmbulo, como valores supremos, o bem-estar e o desenvolvimento, além de elencar no seu artigo $3^{\circ}$, como objetivos fundamentais, o desenvolvimento nacional, a erradicação da pobreza e da marginalização e a redução das desigualdades sociais e regionais (BRASIL, 1998).

Ademais, a Constituição Federal reconhece o direito fundamental ao desenvolvimento, uma vez que, no seu artigo $5^{\circ}, \S 2^{\circ}$, prevê que o catálogo dos direitos fundamentais pode ser ampliado pelos regimes ou princípios adotados, além dos tratados internacionais de que o Brasil é parte, a exemplo da Declaração sobre o Direito ao Desenvolvimento da Organização das Nações Unidas - ONU ${ }^{3}$ (OLIVEIRA, 2009, p. 15).

Influenciada por estes valores, a Constituição de 1988 dedicou um capítulo inteiro à Administração Pública, detalhando suas atribuições através de um extenso conjunto de normas estruturantes que visam ao desenvolvimento nacional e à efetivação dos direitos fundamentais nela previstos.

Apesar de ter sido analítica, Bresser-Pereira (2002, p. 175) afirma que a Constituição não promoveu uma reforma da Administração Pública, já que manteve os ideais burocráticos da década de 1930 e os ideais populistas

\footnotetext{
${ }^{3}$ Artigo $1^{\circ}$. 1. O direito ao desenvolvimento é um direito humano inalienável, em virtude do qual toda pessoa e todos os povos estão habilitados a participar do desenvolvimento econômico, social, cultural e político, a ele contribuir e dele desfrutar, no qual todos os direitos humanos e liberdades fundamentais possam ser plenamente realizados.
} 
da década de 1950, o que resultou numa administração arcaica, centralizada, hierárquica e rígida, priorizando a administração direta em desfavor da indireta e desconsiderando os princípios do gerencialismo que já estavam sendo utilizados em outros países.

Entre as regras burocráticas destacam-se o regime jurídico único para todos os servidores civis da administração pública direta e indireta, a estabilidade sólida, os concursos públicos mais rígidos, novas regras estendidas a toda a Administração, anulando a autonomia das autarquias e fundações públicas. Ocorre que esta mesma Constituição, contraditoriamente, trouxe diversas regras de cunho patrimonialista, consolidando e/ou criando privilégios para os funcionários públicos, em especial para a cúpula dos poderes, como o sistema de aposentadoria integral, a acumulação de aposentadorias, a transformação de empregados celetistas em funcionários estatutários (BRESSER-PEREIRA, 2002, p. 175-176).

Com a queda do muro de Berlim em 1989 e a implosão da União das Repúblicas Socialistas Soviéticas em 1991, as teses de progresso passaram a ser a "globalização", marcada pela abertura de mercado dos países para ingresso no capitalismo internacional, e, como consequência, a redução do papel do Estado a um mínimo, limitando-se a regulação e flexibilizando diversas relações, como a trabalhista; já o bem-estar seria alcançado com a atuação livre das empresas (MELLO, 2013, p. 1.088-1.089).

Com isto, aliado ao aprofundamento da crise fiscal e da própria crise do Estado na década de 1990, além da ineficiência do serviço público, as "transformações" trazidas pela Constituição Federal de 1988 não foram acompanhadas das necessárias mudanças normativas, institucionais e culturais, de forma que não logrou romper com a pecha da corrupção e ausência que caracteriza o Estado brasileiro.

Os governos pós-Constituição de 1988 imprimiram as marcas do neoliberalismo através de profundas mudanças constitucionais que, atualmente, inviabilizam as promessas constitucionais. Pinho (1998, p. 70-71) sustenta que a implementação de um Estado mínimo seguindo os ditames neoliberais é irreal, pois os cidadãos cada vez exigem mais do Estado e as políticas públicas desempenham crescentemente um papel relevante no capitalismo. 
Conforme se observará abaixo, vive-se num contexto em que o Direito estatal se desengaja progressivamente do Estado de Bem-Estar Social e se apoia nas corporações e no capital transnacional. A intervenção pela autoridade só deve ser feita para melhorar a oportunidade de todos, mediante um Estado mínimo que condena qualquer medida protecionista (ARNOUD, 1999, p. 174-176).

\section{OS DESMONTES CONSTITUCIONAIS: A REFORMA GERENCIAL E O RECENTE AJUSTE FISCAL}

Tendo como paradigma o caso inglês Next Steps, e ainda o modelo americano National Performance Review, o governo brasileiro formulou uma reforma administrativa no Executivo federal em 1995, criando o Ministério da Administração Federal e Reforma do Estado - MARE para conduzir uma reforma gerencial que substituísse o modelo de gestão burocrática pela gestão orientada pelo desempenho. Tinha como objetivo lidar com a crise fiscal do Estado, rever o papel do Estado e os mecanismos de controle dos gastos públicos e implementar políticas de privatização e downsizing (REZENDE, 2004, p. 24-30) $)^{4}$.

Conforme Bresser-Pereira (2002, p. 23), a base da reforma gerencial é a ideia de Estado e do seu papel, no sentido de se investigar quais as atividades a serem realizadas diretamente pelo Estado, quais devem ser promovidas ou financiadas, e de quais o Estado deve manter-se alheio. Os presentes critérios para esta investigação são os objetivos políticos fundamentais da sociedade contemporânea, como ordem, liberdade, igualdade, eficiência ou bem-estar.

\footnotetext{
${ }^{4}$ Em resumo, a mudança deveria ser realizada através das performance based organizations - PBOs, que se materializaram pelas organizações sociais e agências executivas; ademais, deveria promover mudanças constitucionais quanto à organização e ao funcionamento da Administração Pública e transformar a cultura burocrática administrativa numa visão gerencial. Necessário ainda transferir uma maior autonomia e accountability aos responsáveis pelas políticas. Para atingir tais objetivos, o plano diretor definiu quatro setores distintos de intervenção: núcleo estratégico, agências responsáveis pela formulação de políticas públicas que não seriam atingidas pelas mudanças; funções exclusivas do Estado, aquelas em que é necessário o poder de polícia (foi proposto um modelo organizado por agências executivas que atuariam com mais liberdade sobre orçamento, pessoal, compras e licitações); atividades não exclusivas do Estado, mas de alta relevância, a cargo de organizações socais; e produção de bens e serviços para o mercado, que seriam privatizados (REZENDE, 2004, p. 30-31).
} 
Para consolidar esta mudança, surge a primeira reforma administrativa depois da Constituição de 1988, através da Emenda Constitucional $\mathrm{n}^{\circ}$ 19/1998, que "modifica o regime e dispõe sobre princípios e normas da Administração Pública, servidores e agentes políticos, controle de despesas e finanças públicas e custeio de atividades a cargo do Distrito Federal, e dá outras providências" (BRASIL, 1998).

Tal emenda trouxe profundas repercussões aos âmbitos estaduais e municipais. Teve como principais pontos: a flexibilização da estabilidade, o fim da obrigatoriedade do regime jurídico único, a avaliação para alcançar estabilidade no final do estágio probatório, a proibição do aumento em cascata, o fim da expressão "isonomia salarial", novas regras sobre teto e subteto da remuneração dos servidores, normas que visam à redução de custos, eficiência e qualidade, além de outras que intentam a descentralização, a participação popular e a proteção do usuário, contratos de gestão etc. (BRESSER-PEREIRA, 2002, p. 208 et. seq.).

Algumas dessas mudanças dependiam de normas infraconstitucionais; outras dependiam de apoio institucional. Rezende (2004, p. 93-94) observa que nesta reforma houve uma forte cooperação tão somente no tocante ao ajuste fiscal, no entanto este é apenas parte do problema. Seria necessária a criação de um novo padrão de articulação e de formulação e implementação das políticas públicas, pois não bastava reduzir os gastos com servidores e diminuir o tamanho do Estado, já que se devia buscar uma melhor alocação dos seus trabalhos para imprimir uma maior eficiência no serviço público.

A reforma falhou, pois não levou em consideração as questões culturais e legais. Consistiu numa proposta ambiciosa que não efetivou a necessária transformação da cultura clientelista e patrimonialista que permeia a máquina burocrática brasileira.

Microrreformas continuam a ser objeto dos mais diversos governos, mas o foco principal, se não o único, é o do ajuste fiscal, ou seja, a redução das despesas públicas, como aconteceu com as inúmeras reformas da previdência social (Emendas 20/1998, 41/2003, 47/2005). Há ainda diversas normas de índole infraconstitucional que são braços das reformas gerenciais, possibilitando downsizing, privatização, terceirização, flexibilização das leis trabalhistas, que, 
em resumo, resultam em mero equilíbrio fiscal, mas que não serão abordadas, já que fogem ao objeto do presente artigo.

Recentemente foi aprovada a Emenda à Constituição no 95/2016 (antiga PEC no 55/2016 e 241/2016), que implementou o rigoroso "Teto dos Gastos Públicos", instituindo um Novo Regime Fiscal no âmbito dos Orçamentos Fiscal e da Seguridade Social da União para a redução e o controle destas despesas, com o congelamento de investimentos sociais para os próximos vinte anos.

Nesta emenda, alguns dispositivos foram acrescentados ao Ato das Disposições Constitucionais Transitórias. Trata-se de um regime que prevê um limite para o exercício de 2017 correspondente aos gastos de 2016, corrigidos em 7,2\%. Para os exercícios posteriores, vigerá o limite do exercício imediatamente anterior, corrigido pelo Índice Nacional de Preços ao Consumidor Amplo - IPCA até 2036 (BRASIL, 2016).

Este novo regime não admite o crescimento de despesas totais e reais acima da inflação; ainda que a economia esteja bem, só haverá investimentos em uma determinada área quando houver cortes nas outras, o que, segundo Mariano (2017, p. 260), “poderá levar ao sucateamento das políticas sociais, especialmente nas áreas da saúde e educação, pondo em risco por completo a qualidade de vida da população brasileira".

Com isso, o novo regime fiscal suspende o projeto constituinte de 1988 de um Estado de Bem-Estar Social, pois, com a fixação do teto, os investimentos necessários à manutenção e à expansão dos serviços públicos serão impedidos, assim como inovações tecnológicas, contratação de pessoal, melhoria da remuneração e carreiras. Engessa até mesmo a autonomia dos orçamentos dos próximos governantes, o que repercute no direito do cidadão de eleger o programa de governo e as políticas públicas para o desenvolvimento econômico (MARIANO, 2017, p. 261).

Ainda segundo Mariano (2007, p. 262), a emenda é uma "antidemocracia econômica", na medida em que impede a manutenção e a expansão das políticas públicas, ao passo que reserva dinheiro público para garantir o pagamento dos credores da dívida pública e exclui do teto das despesas o aumento de capital de empresas estatais não dependentes, com o propósito de comprar 
créditos podres dos Estados e Municípios por meio da emissão de debêntures subordinadas, conforme o $\S 6^{\circ}$ do artigo 102 do ADCT, o que contribuirá ainda mais para o endividamento do Estado brasileiro.

Percebe-se, assim, que a emenda visou, mais uma vez, apenas a um dos focos da reforma gerencial, a saber, a superação da dívida pública em função da redução e do controle dos gastos públicos. Essa medida extremada do constituinte derivado impedirá a satisfação do outro objetivo da reforma, a promoção da eficiência, tendo em vista a ausência de recursos públicos, o que, em última análise, obstará a realização dos objetivos da Constituição de promoção do desenvolvimento e realização dos direitos fundamentais.

Ocorre que o governo brasileiro, assim como vários outros governos de países da América Latina, vem alterando a função tradicional do Estado, visando cada vez mais a sua diminuição, a partir da sua abertura para o setor privado. No entanto, as economias desenvolvidas promovem uma forte intervenção na economia, pois há uma contradição, segundo Batista (1994, p. 19), entre os discursos e as práticas dos países desenvolvidos na área de política fiscal, já que os próprios Estados Unidos são extremamente interventores e possuem um grande déficit orçamentário, financiado pela dívida interna.

O Banco Mundial projetou uma redução das despesas do Estado brasileiro em torno de 13\% do Produto Interno Bruto, comparável ao de países africanos, enquanto os países desenvolvidos, mesmo as economias de livre mercado, gastam em média três vezes mais para assegurar serviços públicos de qualidade, como a França, com 57\%, e os Estados Unidos, "exemplo" de absenteísmo estatal, com 38,8\% (MARIANO, 2017, p. 260).

Ademais, a proposta neoliberal de manutenção do equilíbrio fiscal, como combate à inflação e restabelecimento da confiança na capacidade governamental, é equivocada por não fazer distinção entre despesas correntes e de investimentos. Um nível baixo de despesas e receitas compromete as funções essenciais do Estado: "incentivador do desenvolvimento, promotor do pleno emprego e da justiça social”. Em verdade, reduzir em níveis tão acentuados o tamanho do Estado compromete até mesmo a sua função clássica de promotor da segurança. A incorporação dessas ideias em um cenário latino-americano transforma a concepção de um Estado mínimo num Estado-gendarme, que 
serve tão somente para a manutenção da ordem pública interna (BATISTA, 1994, p. 19-20).

Em crítica às políticas agressivas de ajustes fiscais, Oliveira considera como superada a hegemonia do culto extremado ao mercado como principal ator do desenvolvimento, e defende "uma revalorização do papel do Estado como agente incentivador, promotor e condutor do desenvolvimento econômico e social" (2009, p. 3-4).

Na mesma linha, Mazzucato sustenta a visão de um Estado empreendedor, critica a concepção de um Estado baseado em cortes de orçamento e reconhece o seu poder para resolver problemas complexos, como o de colocar o homem na Lua e de cuidar da mudança do clima. Para tanto, são necessários instrumentos políticos específicos e ousadia a fim de garantir o crescimento através de investimentos "inteligentes" e "inclusivos" (2014, p. 263).

Afinal, apenas com o desenvolvimento as pessoas podem expandir e experimentar as liberdades reais, tanto as liberdades substanciais, como o fim da subnutrição, da morte prematura e da fome, como as liberdades instrumentais, através das oportunidades sociais, das liberdades políticas e das facilidades econômicas (SEN, 2010, p. 54-60).

A Emenda Constitucional no 95/2016 é uma medida que aprofunda a crise econômica para atender ao capitalismo rentista, mantendo o "estado de exceção econômico", tão habitual na América Latina. Trata-se de "um obstáculo neocolonialista ao desenvolvimento soberano de economias periféricas" (MARIANO, 2017, p. 277).

Enquanto os países de centro vivem em situação de normalidade, os Estados periféricos da América Latina se acham em permanente estado de exceção, uma vez que prevalece a ditadura econômica dos mercados; as decisões são tomadas para salvar os mercados através dos poderes constitucionais; há uma subordinação do Estado ao mercado e do direito interno ao capital financeiro, o que exige flexibilidade, reduz a interferência da soberania popular e limita os direitos individuais, no intuito de garantir a propriedade privada e a acumulação capitalista. Trata-se do Estado de exceção na visão de Bercovici (2005, p. 4-5).

Nesta linha, as transformações do mundo político, econômico e finan- 
ceiro geram repercussões na vida social dos cidadãos. A integração econômicofinanceira transfronteiriça marca cada vez mais os mercados nacionais, a exigir que agentes econômicos revisem suas estratégias. O desafio está em governar a economia quando não se manda no mercado mundial. Com um "governo de empresa", passa-se de "um modelo de patrimonialização para um modelo de contratualização, o que requer um equilíbrio entre a liberdade de mercados e a prestação de bens públicos" (ARNOUD, 1999, p. 160).

Neste contexto de reformas administrativas constitucionais, verificadas as origens e as consequências dos recentes desmontes do Estado brasileiro, resta analisar se o cenário de estado de exceção econômico e de crise constituinte legitima as opções tomadas pelo poder constituinte derivado.

\section{LIMITES DA REFORMA CONSTITUCIONAL: A CRISE CONSTITUINTE E O RETROCESSO SOCIAL}

Conforme visto acima, as reformas constitucionais estão a desfazer os projetos originários previstos pelo poder constituinte, em especial as reformas administrativas. Ao implantarem um rigoroso ajuste fiscal, violam o direito ao desenvolvimento, impedindo a efetivação de direitos sociais básicos previstos na ordem constitucional.

Ocorre que, apesar de a doutrina apontar o poder constituinte como o principal fundamento jurídico do Estado moderno, trata-se de um poder "transconstitucional", pois, apesar de originário, já não há a possiblidade de uma independência absoluta em relação a outras ordens constitucionais (SALDANHA, 1986, p. 83-84).

Em crítica à doutrina nacional, Bercovici (2013, p. 310-314) afirma que se procura explicar o tema poder constituinte através de uma visão europeia, em especial com base na experiência francesa. Com isso, o foco gira em torno da reforma da Constituição e dos seus limites, e praticamente não há estudos sobre a legitimidade do poder constituinte. A "transposição da visão francesa para o Brasil gerou uma discussão doutrinaria estéril, sem qualquer vinculação com nossa experiência política e constitucional". Quijano (2005, p. 13) entende que refletir a perspectiva eurocentrista na América Latina sem considerar os 
traços distintivos inviabiliza identificar e resolver os verdadeiros problemas.

Outra disfunção trazida pelos juristas tradicionais é o fato de só reconhecer os poderes constituintes explícitos (originário ou derivado); no entanto, há outro poder que traz uma Constituição gravada na consciência social e na competição entre os grupos da sociedade, uma vez que a Constituição verdadeira é aquela que "está simultaneamente no texto e na realidade", sob pena de perda de juridicidade e eficácia, a se transformar em um "fantasma de papel" (BONAVIDES, 2010, p. 187-188).

Afinal, as teorias econômicas, sociais, políticas e jurídicas não surgem do nada; trata-se de acontecimentos no seio da sociedade que refletem o seu ambiente cultural. Nos países subdesenvolvidos, uma grande parte dos ingredientes culturais é importada dos países desenvolvidos, pois, apesar da soberania conquistada com a sua independência, vivem ainda sob a órbita de algum "país-guru" que lhes fornece os ideais do "modelo econômico"; estes, por sua vez, servem como diretrizes para o Direito. É a "síndrome de dependência", do "servilismo intelectual", fruto, muitas vezes, de um complexo de inferioridade (MELLO, 2013, p. 1.084-1.085).

O neocolonialismo encontra ambiente muito propício para medrar em nosso meio cultural e, pois, no seio do Direito Administrativo brasileiro, por termos, ainda, uma mentalidade acentuadamente marcada pela subserviência ideológica, típica do subdesenvolvimento de país que persiste pagando um pesado tributo ao colonialismo. (MELLO, 2013, p. 1.096-1.097).

É neste contexto que Bonavides (2010, p. 188-189) trata da crise constituinte, um processo que não termina com a promulgação da Constituição e que ocorre quando as instituições políticas não estão alicerçadas num poder legítimo, quando falta aprovação popular; é "devastadora de textos, emendas e fórmulas que a retórica e a imaginação da classe política fazem brotar".

A questão é que há uma confusão entre a teoria material da Constituição, que tem por base o positivismo sociológico, e a teoria formal da Constituição, alicerçada num positivismo jurídico. A crise somente pode ser resolvida 
se houver a recuperação da legitimidade. Entretanto, o que se percebe é que há uma falha em promover o fim dos males políticos e sociais do Estado, em especial nos países subdesenvolvidos, uma vez que as Constituições não possuem força suficiente para resolver os problemas da realidade (BONAVIDES, 2010, p. 191-193).

Formalmente não existem controvérsias quanto ao titular do poder constituinte, uma vez que o único legítimo é o povo ou a nação. De outra banda, do ponto de vista material, a titularidade sofre limitações explícitas e implícitas que influenciam o constituinte formal; muitas vezes, estes chancelam a vontade de outros poderes paralelos e externos. "A crise constituinte é aqui, por conseguinte, a crise da titularidade do poder". Essa crise também se manifesta quanto ao seu objeto, porquanto as normas programáticas de prestações sociais suplantam a capacidade do Estado de cumprir com tais prestações, tornando-se inadimplente (BONAVIDES, 2010, p. 194-195).

O Consenso de Washington (de 1989) é um grande exemplo de limitação do poder constituinte, gerado a partir da reunião entre os funcionários do governo americano e do Fundo Monetário Internacional - FMI, Banco Mundial e Banco Interamericano de Desenvolvimento. Apesar de não possuir caráter deliberativo, detém uma grande força simbólica para a adoção da proposta neoliberal nos países latino-americanos como condição para a cooperação financeira (BATISTA, 1994, p. 5-6).

A crise constituinte na maior parte dos países em desenvolvimento é decorrente de um estado de exceção econômico; as decisões são tomadas de acordo com a conveniência dos interesses econômicos neoliberais e não de acordo com a vontade do povo, no que se verifica que a crise da Constituição é a crise da própria soberania.

Esse problema tem como origem os limites históricos e estruturais que o poder constituinte encontra para manifestar a vontade soberana do povo; daí se enxergar uma "soberania bloqueada" em virtude das diversas restrições internas e externas que sofre. Ademais, percebe-se que o estado de exceção econômico permanente a que o Brasil está submetido dificulta a concretização do projeto constitucional (BERCOVICI, 2013, p. 314-319).

Em análise semelhante, Arnoud (1999, p. 154-155) sustenta que há um 
comprometimento da autonomia dos Estados em decorrência da interdependência em face da economia globalizada. Não se trata de um problema formal da soberania dos Estados, mas sim de que a sua autoridade diminui devido à "porosidade das fronteiras", à "dificuldade de controlar os fluxos transfronteiriços monetários, de mercadorias e de informação, aos avanços tecnológicos".

Ainda considera a questão da soberania estatal como "ponto central de toda a problemática da regulação pelo direito" e traz dúvidas sobre sua autoridade, oportunidade, efetividade e eficácia, até porque são os governos dos países centrais, as empresas transnacionais, instituições como FMI, Banco Mundial e G7, que tomam a maior parte das decisões que afetam a vida das pessoas, sem que elas saibam disso ou consintam nisso. "Está claro que os 'diktats' externos suplantam muitas vezes o Estado na sua soberania de regulação social"' (ARNOUD, 1999, p. 171).

O idealizador da reforma gerencial da década de noventa, Bresser-Pereira, sustenta que a motivação inicial para a reforma do Estado tem matriz econômica, fruto do processo de globalização do final do século passado, uma vez que na "restrição-eficiência" devem-se utilizar os recursos de forma mais econômica ou racional, em virtude da lógica capitalista da competição que o mundo contemporâneo impôs aos Estados e às empresas (2002, p. 152).

Bonavides (2001, p. 14) adverte que

Estamos em situação constitucional muito mais grave: a recolonização é iminente, a passividade do povo não tem paralelo na história, as camadas governantes desmantelam a máquina do poder, ferem a Constituição, aviltam o Estado, e as elites aplaudem; a classe representativa não reage, e é cumplice no crime da desnacionalização. De tal sorte que o País todo é uma capitania. A sede de poder está fora do território nacional e ninguém sabe que surpresa amanhã nos aguarda, ao sabor das flutuações especulativas das bolsas de valores, colocadas debaixo do influxo e domínio do capital estrangeiro.

Ocorre que o princípio cardeal de uma Constituição é o reconhecimento da soberania popular, e não somente o discurso retórico de que "todo poder emana do povo", devendo essa soberania atingir três dimensões: "ne- 
cessidade de consentimento popular como condição de legitimidade da atribuição e do exercício do poder, em todos os níveis; a participação popular no exercício das funções públicas; e a garantia dos direitos e liberdades fundamentais" (COMPARATO, 1986, p. 16-17).

$\mathrm{O}$ “poder constituinte atua de forma permanente. Ele se refere ao povo concreto, com autoridade e força para estabelecer a Constituição, manter a sua pretensão normativa e revogá-la" (BERCOVICI, 2013, p. 309). No entanto, o que se tem na prática é o poder constituinte influenciado pelos mercados e não pela vontade popular, conforme se observa nas recentes reformas administrativas e, em especial, no ajuste fiscal.

Deve-se levar em consideração que o titular do poder constituinte pode ser tanto o povo quanto a assembleia, ao mesmo tempo e com funções distintas, a partir de uma exigência de participação popular com capacidade de deliberação política. $\mathrm{O}$ poder constituinte deve pertencer a uma entidade consciente (SALDANHA, 1986, p. 72-73).

Ocorre que ao se preocupar apenas em definir os limites da reforma constitucional, a doutrina jurídica tradicional não considera o povo e o poder constituinte como "categorias jurídicas", como se não tivessem lugar no direito público. Ao separar o conceito de Constituição do conceito de poder constituinte, exclui a origem popular como validade da Constituição. O poder constituinte em um Estado constitucional não é pensado como um poder direto e proveniente do povo, uma vez que é exercido apenas indiretamente, de forma representativa (BERCOVICI, 2013, p. 305-308).

Neste contexto, Saldanha (1986, p. 73-76) destaca o problema de saber até que ponto o povo tem consciência das condições histórico-culturais necessárias à realização da democracia constitucional. Tendo em vista a soberania popular, questiona a participação do povo na ação constituinte, ou, ao menos, se não necessitaria da homologação nacional.

Entretanto, o poder constituinte do povo nunca conseguiu derrotar o patrimonialismo e o aparelhamento do poder no Brasil. O povo constitui tão somente massa de manobra da classe dirigente; para sair deste círculo vicioso, é "necessário o deslocamento da titularidade da soberania de um grupo para a comunidade como um todo" (FAORO, 2013, p. 207-208). 
Esta crise constituinte, da soberania popular e de legitimidade, ficou evidenciada nos movimentos populares contrários às PECs n ${ }^{0}$ 55/2016 e 241/2016, que deram origem à Emenda à Constituição no 95/2016. Durante este período, as universidades públicas e os institutos federais foram ocupados pelos estudantes e ocorreram várias paralisações com movimentos sociais em todo o Brasil, com destaque para o "Ocupa Brasília". Sem discussões e a participação da sociedade como um todo, entretanto, a emenda foi aprovada com certa facilidade, já que sua tramitação não durou nem dois meses.

Na mesma linha, o Senado Federal realizou consulta pública em seu sítio eletrônico: dos 369.488 votantes, somente 23.770 votaram a favor da referida emenda; 354.718 votantes explicitaram que não deveria ser aprovada, ou seja, aproximadamente $96 \%$ daqueles que tiveram acesso à pesquisa entenderam pela inviabilidade da alteração (BRASIL, 2017).

Ademais, esta última reforma carece de legitimidade democrática, pois não foi o projeto político e constitucional vencedor nas últimas eleições. Além de bater de frente com o espírito da Constituição de 1988 e das suas reformas gerenciais posteriores, cria obstáculos para a criação de um Estado de Bem-Estar Social, bem como de uma economia soberana e independente (MARIANO, 2017, p. 280).

Ao tratar sobre as "cláusulas de eternidade" de um Estado constitucional, Häberle (2003, p. 146-147) entende que são conteúdos típicos a dignidade humana e os direitos humanos, o princípio democrático, a divisão de poderes e o Estado social de direito, ainda que não estejam escritas, uma vez que devem ser interpretados a partir de um enfoque material, por comporem o "espírito" da Constituição.

As reformas e ajustes fiscais em exame, ao serem efetivados, impedirão a realização de direitos humanos básicos, dada a incapacidade financeira do Estado de promover tais direitos, no que se pode considerar uma violação não literal das cláusulas pétreas previstas na Constituição de 1988, implicando retrocesso social e impedindo uma atuação eficiente dos serviços públicos.

Há ainda uma distinção trazida por Saldanha (1986, p. 86-90) entre poder constituinte e poder de reforma. Essa diferença é importante em razão da crítica daqueles que designam o poder de rever ou formar uma Constitui- 
ção como constituinte, porquanto o poder de reforma é um poder para apenas refazer parcialmente uma Constituição feita; é, nos seus termos, um poder constituído, anexo ao constituinte, para evitar a confecção de uma nova Constituição. Conclui que existem limites ao poder constituinte e os esquematiza em dois polos: um, de ordem internacional, uma vez que somente pode atuar na sua órbita de soberania correspondente; e outro, de ordem humana individual, já que os princípios gerais do Direito devem ser observados.

Conforme tratado acima, as reformas administrativas, em especial os ajustes fiscais trazidos, apesar de não alterarem formalmente o texto da Constituição neste ponto, impedirão a realização dos direitos fundamentais - sobretudo o direito ao desenvolvimento restará frontalmente aviltado, inviabilizando os serviços públicos já tão deficientes.

Registre-se ainda a falha do discurso da necessidade de acompanhar as demais nações do mundo, já que buscam parâmetros em economias desenvolvidas, onde os direitos fundamentais já foram assegurados, incorporandose ao seu catálogo um número bem superior de prestações sociais que no Brasil ainda se acham em processo de implantação.

Assim, as recentes alterações promovem mudanças vedadas pelo texto constitucional e trazem um retrocesso social, quando deveriam buscar a evolução da Administração Pública para imprimir uma maior eficiência às prestações públicas, implementando os direitos fundamentais previstos na Constituição de 1988.

\section{EQUILÍBRIO NECESSÁRIO ENTRE REFORMAS ADMINISTRATIVAS, CRISE CONSTITUINTE E CRISE FISCAL}

Sem pretensão de ser exaustivo, mas também para não pecar por ser tão somente descritivo, propõem-se algumas possíveis soluções, mais no sentido de reflexões, para que uma reforma administrativa constitucional seja realizada ao mesmo tempo com suporte na soberania popular e com equilíbrio fiscal.

Conforme visto acima, ao passo que um dos principais objetivos da Administração Pública é a proteção do patrimônio público, somente com a 
democracia será possível alcançar tal objetivo, pois tão só num regime democrático surge a reforma gerencial. Bresser-Pereira (2002, p. 81) trata de um novo tipo de direito de cidadania, que são os direitos republicanos, "o direito que cada cidadão tem de que o patrimônio público seja usado para fins públicos ao invés de ser capturado por interesses privados".

Tais objetivos pressupõem um regime democrático e fortalecem o próprio regime, uma vez que, no conceito clássico de democracia como um governo do povo para o povo, a res pública, o patrimônio público ou o interesse público só se realizam mediante um bom uso destes recursos, impedindo qualquer tipo de apropriação privada destes.

Para Bresser-Pereira (2002, p. 151-152), a reforma gerencial "só faz sentido quando aprofunda as formas de democracia representativa e de democracia direta ou controle social", o que contribui para a chamada "eficiência" administrativa e para a afirmação democrática dos direitos de cidadania. Sustenta ainda que as reformas burocráticas ocorreram no âmbito de regimes políticos não democráticos ou pré-democráticos. Defende que o regime democrático foi a grande conquista política do século $X X$, que a lógica econômica não pode prevalecer e que as decisões políticas deverão ser fruto de debates públicos e da formação de consensos ou de maiorias.

Ocorre que um dos maiores desafios da democracia participativa é a formação de uma cidadania ativa e informada. Trata-se de um ideal oposto ao funcionamento habitual das sociedades de massa modernas. É importante que se deem condições de participar dos espaços públicos de discussão; os poderes públicos devem reforçar as capacidades de expressão e de ação (BLONDIAUX, 2013, p. 61-62).

Há ainda problemas oriundos do reflexo eurocentrista na América Latina, como a questão do Estado-nação, uma sociedade nacionalizada e politicamente organizada, com instituições modernas de cidadania e democracia política. No seu processo de construção deve existir uma relativa homogeneização da população, com o objetivo de produzir uma identidade comum, forte e duradoura. É necessário ainda um processo de democratização da sociedade para a nacionalização e a organização política, a partir de uma descolonização e de uma redistribuição radical do poder. 
Na realidade, cada categoria usada para caracterizar o processo político latino-americano tem sido sempre um modo parcial e distorcido de olhar esta realidade. Essa é uma consequência inevitável da perspectiva eurocêntrica, na qual um evolucionismo unilinear e unidirecional se amalgama contraditoriamente com a visão dualista da história; um dualismo novo e radical que separa a natureza da sociedade, o corpo da razão. (QUIJANO, 2005, p. 21-22).

Na sua proposta de anteprojeto para a Constituição de 1988, Comparato previu vários instrumentos de participação popular, com destaque para a atribuição de legitimidade ativa do povo a fim de propor leis, inclusive quanto à possibilidade de emendas constitucionais, e, em especial, à atribuição aos cidadãos do poder de sanção, através de referendo popular ou plebiscito. Nestes termos, as emendas constitucionais relativas à soberania, direitos e deveres do cidadão, proteção da pessoa humana e ordem econômica e social precisariam de referendo para ser validadas (1986, p. 16-17).

Tais reformas trazem profundas repercussões ao âmbito dos demais direitos, ferindo até mesmo a proteção da pessoa humana, com o contingenciamento oriundo dos recentes ajustes fiscais. Assim, o referendo das reformas administrativas constitucionais, como forma de manifestação da democracia participativa, é um instrumento que poderia resolver, em parte, a crise constituinte, devolvendo ao povo o seu papel de real legitimado para definir os destinos de sua nação.

É verdade que uma redução de gastos é inevitável, mas tal redução pode ser viabilizada através dos cortes dos privilégios de poucos, como as diversas verbas de gabinetes dos Poderes Executivos e Legislativo, bem como os tantos auxílios concedidos aos membros do Poder Judiciário e do Ministério Público e outros funcionários que compõem a cúpula dos Poderes, práticas patrimonialistas preservadas institucionalmente.

Outra solução é buscar o incremento de receitas, não com a majoração da carga tributária, mas sim com a devida implementação daqueles que já existem, como, por exemplo, do Imposto sobre Grandes Fortunas. Além disso, cumpre resolver as questões de "elevado limite de isenção, baixas alíquotas, 
a não incidência sobre pessoas jurídicas, a transferência de riqueza financeira para paraísos fiscais e a subavaliação dos imóveis" (MARIANO, 2007, p. 276).

Desta forma, o equilíbrio fiscal pode ser alcançado com o corte de despesas abusivas e o incremento de receita, de um modo que não atinja a parte da população que mais precisa dos benefícios sociais.

Outro ponto igualmente importante é um maior controle das contas públicas, não só através do controle interno e externo, como previsto pela Constituição, mas também mediante um maior controle popular, mediante uma maior disseminação de práticas de transparência e publicidade.

Existem diversas formas de reverter esta crise sem trazer impactos negativos à vida do cidadão brasileiro. Cano (2014, p. 30-32) sustenta que uma nova política industrial deve ser acompanhada por uma política macroeconômica que lhe dê sustentação política e econômica. O Brasil entrou na globalização, assumindo compromissos internacionais como deveria, abrindo a conta de capital, perdendo o controle sobre a entrada e a saída de capital internacional e nacional, sobre remessas de lucros e fluxos de investimento, bem como sobre a soberania na sua política cambial, fiscal e monetária. Os governos depois de 1990 entregaram-se ao sistema financeiro; cabe romper com esse acordo, tendo em vista que os horizontes políticos internacionais são imprecisos e imprevisíveis.

É possível enfrentar a crise atual voltando-se, em especial, para o mercado interno, em função da imensa população e território, para além da boa diversidade de recursos naturais. Tal medida deve ser complementada por um "Programa Nacional de Desenvolvimento", a partir de "uma estratégia específica de exportações, introjeção tecnológica e uma priorização setorializada e regionalizada de infraestrutura e alta tecnologia". Elementos que não considerarão apenas crescimento e produtividade, mas que visem atender "às necessidades básicas da população e do país, como habitação popular, saneamento básico, educação e saúde pública, que, sem dúvida, deveriam encimar a agenda de planejamento" (CANO, 2014, p. 32-33). 


\section{CONSIDERAÇÕES FINAIS}

Este artigo teve como principal objetivo analisar as reformas administrativas gerenciais no Brasil, em especial os ajustes fiscais realizados sob a perspectiva da crise constituinte em um estado de exceção econômico permanente que culminou com a implantação do "Teto dos Gastos Públicos", trazido pela Emenda Constitucional no 95/2016.

Verificou-se que em menos de um século o Brasil passou por diversas transformações na estrutura da Administração Pública: de uma burocracia weberiana, que tinha como principal objetivo a sua profissionalização e romper com o patrimonialismo vigente, até a mais recente reforma gerencial, com grande foco na mudança institucional visando ao desempenho e no ajuste fiscal a partir do controle e da redução dos gastos públicos.

Os anos 1980 foram decisivos para a Administração Pública em decorrência do declínio generalizado do desempenho, impulsionado pela insatisfação com os resultados do modelo keynesiano de desenvolvimento e pela expansão das ideologias pró-mercado. Surgiu a necessidade de uma nova configuração do Estado, que buscava se afastar do Estado de Bem-Estar Social, devido à "mercantilização" das mais diversas áreas da vida social.

Em direção oposta a esse movimento, a Constituição Federal de 1988 pretendeu imprimir um Estado prestador de várias demandas sociais, garantindo diversos direitos que dependiam de uma atuação forte do Estado. Para tanto, detalhou as atribuições da Administração Pública através de um extenso conjunto de normas estruturantes, visando ao desenvolvimento nacional e à efetivação dos direitos fundamentais nela previstos.

Entretanto, o aprofundamento da crise fiscal fez com que diversas reformas constitucionais fossem implementadas desde o nascedouro da Constituição, reconfigurando o Estado brasileiro e subvertendo o seu texto, uma vez que, tendo como base as premissas do gerencialismo, teve como critério básico das alterações o ajuste fiscal, o que compromete as suas missões constitucionais mais basilares.

A mais recente reforma, a da Emenda Constitucional no 95/2016, que implantou o Teto dos Gastos Públicos com limites no orçamento para os pró- 
ximos vinte anos, visou apenas a um dos focos da reforma gerencial, a saber, a superação da dívida pública em razão da redução e do controle dos gastos públicos. Essa medida extremada do constituinte derivado impedirá a satisfação do outro objetivo da reforma, a promoção do desempenho, tendo em vista a ausência de recursos públicos, o que, em última análise, obstará a realização dos objetivos da Constituição Federal.

Percebeu-se que no contexto de crise constituinte, essas decisões não são feitas com base na soberania popular, já que as instituições políticas não estão alicerçadas em um poder legítimo. Este problema se dá, em especial, nos países em desenvolvimento, pois as Constituições não possuem força suficiente para resolver os problemas da realidade, e o poder constituinte acaba muitas vezes por chancelar a vontade de outros poderes paralelos e externos, a exemplo do Consenso de Washington.

Nessa crise de legitimidade, as decisões são, geralmente, tomadas ao sabor das exigências do mercado, devido ao estado de exceção econômico permanente vivenciado por grande parte dos países em desenvolvimento, uma vez que a "soberania" é bloqueada em virtude das diversas restrições internas e externas que sofrem.

A Emenda do Teto dos Gastos Públicos é um grande exemplo de uma opção que desprezou a vontade popular em benefício do interesse de atores privados, implicando uma redução do Estado com repercussões negativas na prestação dos serviços públicos. Além disto, as recentes alterações promovem mudanças vedadas pelo texto constitucional e trazem um retrocesso social.

Por fim, o problema não está nas reformas administrativas, nem mesmo no apelo do ajuste fiscal, que é necessário em situações de crise econômica. As reformas administrativas trouxeram certos avanços, no entanto, urge uma nova reforma da Administração Pública que promova um maior desempenho mediante a eliminação da carga patrimonialista, desvencilhando-se das experiências eurocêntricas que não refletem a realidade brasileira, garantindo uma democracia participativa através de uma cidadania ativa que proporcione um maior controle, com a promoção da qualidade dos serviços públicos e visando à efetivação dos direitos sociais fundamentais. 


\section{REFERÊNCIAS}

ARNAUD, André-Jean. O Direito entre Modernidade e Globalização: lições de filosofia do Direito e do Estado. Renovar: Rio de Janeiro, 1999.

BATISTA, Paulo Nogueira. O consenso de Washington: a visão neoliberal dos problemas latino-americanos. Caderno da Dívida Externa, n. 69, PEDEX, São Paulo: Peres, 1994.

BAVA, Silvio Caccia. Convulsões sociais. Le monde diplomatique Brasil. Março, 2017.

BERCOVICI, Gilberto. O estado de exceção econômico e a periferia do capitalismo. Boletim de Ciências Econômicas. Vol. 48 (2005). Disponível em: < https:/ / digitalis-dsp. uc.pt/bitstream/10316.2/24875/1/BoletimXLVIII_Artigo1.pdf?ln=pt-pt>. Acesso em: 2 mar. 2017.

O Poder Constituinte do povo no Brasil: um roteiro de pesquisa sobre a crise constituinte. Lua Nova, São Paulo, n. 88, p. 305-325, 2013 . Disponível em: <http://www.scielo.br/scielo.php?script=sci_arttext\&pi$\mathrm{d}=$ S0102-64452013000100010\&lng=en\&nrm=iso>. Acesso em: 1 mar. 2018. http:/ / dx.doi.org/10.1590/S0102-64452013000100010.

BONAVIDES, Paulo. Curso de Direito Constitucional. São Paulo: Malheiros, 2010.

. Do Estado liberal ao Estado social. São Paulo: Malheiros, 2014.

Do país constitucional ao país neocolonial: a derrubada da Constituição e a recolonização pelo golpe de Estado institucional. São Paulo: Malheiros, 2001.

BORON, Atilio A. El nuevo orden imperial y cómo desmontarlo. Trabalho apresentado no Foro Social Mundial no dia 27 de janeiro de 2001.

BRASIL. Constituição (1988). Constituição da República Federativa do Brasil. Brasília, 5 de outubro de 1988. Disponível em: <http:/ / www.planalto.gov.br/ccivil_03/ constituicao/ConstituicaoCompilado.htm>. Acesso em: 28 fev. 2018.

BRASIL. Emenda Constitucional no 19 (1998). Constituição da República Federativa do Brasil. Brasília, 4 de julho de 1998. Disponível em:

<http://www.planalto.gov.br/ccivil_03/constituicao/emendas/emc/emc19. htm>. Acesso em: 28 fev. 2018. 
BRASIL. Atividade Legislativa. Senado Federal. Brasília. Disponível em:

< https://www25.senado.leg.br/web/atividade/materias/-/materia/127337>. Acesso em: 28 fev. 2018.

CANO, Wilson. Soberania e política econômica na América Latina. São Paulo: Editora Unesp, 2000.

. (Des)Industrialização e (Sub)Desenvolvimento. Texto para Discussão. IE/Unicamp, Campinas, n. 244, set. 2014.

COMPARATO, Fábio Konder. Muda Brasil: uma constituição para o desenvolvimento democrático. Editora Brasiliense: São Paulo, 1986.

FAORO, Raymundo. A República inacabada. São Paulo: Globo, 2013.

HÄRBELE, Peter. El Estado constitucional. Hector-Fix-Fierro (trad.). Peru; UNAM, 2003.

HARVEY, David. O neoliberalismo: história e implicações. São Paulo: Edições Loyola. 2008.

MARIANO, Cynara Monteiro. Emenda constitucional 95/2016 e o teto dos gastos públicos: Brasil de volta ao estado de exceção econômico e ao capitalismo do desastre. Revista de Investigações Constitucionais, Curitiba, vol. 4, n. 1, p. 259-281, jan./abr. 2017. DOI:10.5380/rinc.v4i1.50289.

MAZZUCATO, Mariana. O Estado empreendedor: desmascarando o mito setor público vs. setor privado. Tradução de Elvira Serapicos. São Paulo: Portfolio-Penguin, 2014.

MELLO, Celso Antônio Bandeira de. Curso de Direito Administrativo. 30a ed. São Paulo: Malheiros, 2013.

OLIVEIRA, Gustavo Henrique Justino de. Direito ao desenvolvimento na Constituição brasileira de 1988. In Revista Eletrônica de Direito Administrativo Econômico. Salvador: 2009.

PINHO, José Antonio Gomes de. Reforma do aparelho do estado: limites do gerencialismo frente ao patrimonialismo. O\&S. V. 5. No 12, Maio/Agosto de 1998.

QUIJANO, Anibal. Colonialidade do poder, eurocentrismo e América Latina. En libro: A colonialidade do saber: eurocentrismo e ciências sociais. Perspectivas latino-americanas. Edgardo Lander (org.). Colección Sur, CLACSO, Ciudad Autónoma de Buenos Aires, Argentina. setembro 2005. 
REZENDE, Flávio da Cunha. Por que falham as reformas administrativas? Rio de Janeiro: Editora FGV, 2004.

SALDANHA, Nélson. O poder constituinte. São Paulo: Revistas dos Tribunais, 1986.

SEN, Amartya. Desenvolvimento como liberdade. Tradução Laura Teixeira Motta. São Paulo: Companhia das Letras, 2010. 